\title{
A Two-Stage Method for Considering Cardinality in Portfolio Optimization of Mutual Funds
}

\author{
Amir Alimi ${ }^{1}$ \\ ${ }^{1}$ Department of management, Ferdowsi university of Mashhad, Iran \\ Correspondence: Amir Alimi, Department of management, Ferdowsi university of Mashhad, Mashhad, Iran. \\ E-mail: amiralimi2005@yahoo.com
}

Received: January 17, 2015

Accepted: February 3, 2015

Online Published: July 30, 2015

doi:10.5539/mas.v9n8p289

URL: http://dx.doi.org/10.5539/mas.v9n8p289

\begin{abstract}
Mutual funds are important financial institutes. There are several methods for performance evaluation of mutual funds such as portfolio optimization. Portfolio optimization has a basic model that has completed up to now. One of completions is adding cardinality constraint to the model. Considering cardinality in portfolio optimization model makes it an integer programming problem that solving it, is hard and makes the efficient frontier discontinuous. In current study in first stage we rank the mutual funds with VIKOR method and based on 5 characteristics: rate of return, variance, semivariance, Treynor ratio and Sharpe ratio. In second stage according to cardinality level best ranked mutual funds are chosen. A mean-semivariance portfolio optimization model is written using chosen funds. This model is solved using fuzzy technique programming and efficient frontier is obtained. Real data from NASDAQ based on 92 mutual funds are used to illustrate the effectiveness of proposed methodology. Results show that the efficient frontier obtained from our methodology is continuous and near to unconstrained efficient frontier.
\end{abstract}

Keywords: mutual fund, VIKOR method, mean-semivariance, cardinality, fuzzy programming technique

\section{Introduction}

The role of mutual funds in financial markets is undeniable. Mutual funds are financial institutes that help investors to have an appropriate portfolio. Performance evaluation of mutual funds has become a serious subject in recent years. Researchers have applied new methods to choose superior funds. Murthi et al. (1997) used Data Envelopment Analysis (DEA) as a non- parametric method and Jenson alpha and Sharpe as indices. Basso \& funari (2001) used DEA method too. They defined their model based on Jenson alpha, Treynor, Sharpe and semivariance indices. Chang et al. (2010) evaluated mutual funds using extended TOPSIS method and based on Jenson alpha, Sharpe and Treynor indices and Information ratio. In mutual funds portfolio optimization problem Xia et al. (2001) considered transaction cost and Chen \& Huang (2009) used cluster analysis in their model. In this article cardinality subject is considered in portfolio optimization of mutual funds. In this study a two-stage method is defined. In first stage VIKOR method is used.

The VIKOR method is a new and famous method that placed on Multi Attribute Decision Making (MADM) methods. Opriovic (1998) used this method for the first time and opriovic \& Tzeng (2002) extended it. In first stage of this study mutual funds are ranked based on VIKOR method using 5 characteristics: rate of return, variance, semivariance, Treynor index and Sharpe index. In second stage a multi-objective portfolio optimization model is used.

Markowitz $(1952,1959)$ proposed portfolio selection problem in a mathematical model. There are many studies that have done to improve and complete this model. For example Benati \& Rizzi (2007) used value at risk (VaR) as a measure of risk. Lin \& Liu (2008) wrote a portfolio optimization model with minimum transaction lots and solved it with Genetic Algorithm. Gupta et al. (2008) entered liquidity and minimal and maximal fraction of the asset that should be invested in an asset in their model. They solved their model using fuzzy mathematical programming. Jana et al. (2009) proposed a possibilistic model with transaction cost and entropy function in objective functions. Chang et al. (2009) considered different risk measures in their model such as variance, semivariance, variance with skewness and absolute deviation, and solved it using genetic algorithm. An important subject that has investigated in many portfolio optimization studies is cardinality. 
Cardinality means the number of assets that should be held in optimized portfolio. When the problem is large scale capital allocation based on the results of problem is difficult. For example, when we have 100 assets results show that we should allocate lower than 1 percent of our capital in some of assets. In this situation portfolio management is very difficult. To avoid this problem researchers define a constraint named cardinality. Cardinality is considered as a constraint in many researches such as: Gupta et al. (2008), Chang et al. (2009), Branke et al. (2009), Golmakani \& Fazel (2011), Yang et al. (2011), Anagnostopoulos \& Mamanis (2011) and Woodside-Oriakhi et al. (2011). Anagnostopoulos \& Mamanis (2010) proposed cardinality as an objective function that should be minimized. Chang et al. (2000) investigated the differences between basic portfolio optimization models and cardinality constrained models. They illustrated that when there is a cardinality constraint the efficient frontier is discontinuous. In their study 2 weaknesses are mentioned for basic Markowitz's model: 1- the assumption of normality for returns and 2- constraints such as cardinality that make the model an integer programming problem. In current study to avoid the first weakness semivariance is considered as a downside risk measure and to avoid the second, cardinality is considered before optimization.

Considering cardinality in portfolio optimization model change it to an integer programming problem with discrete variables. Because solving this type of problems and obtaining efficient frontier is difficult and time-consuming, in this study a two-stage method is used. In first stage mutual funds are ranked based on 5 characteristics and with VIKOR method. In second stage according to cardinality level best mutual funds based on VIKOR ranking are chosen. A mean- semivariance portfolio optimization model is applied for these mutual funds. Fuzzy technique programming solved this model and efficient frontier is obtained.

This paper is organized as follows: In section 2 the first stage of our methodology is described. In this section the VIKOR method and its attributes are discussed completely. In section 3 the basic portfolio optimization problem, mean-semivariance model and cardinality constraint are presented and fuzzy technique programming is considered as our solving method. To illustrate the proposed method a numerical example is solved in section 4 . Section 5 presents our conclusions.

\section{First Stage: Ranking Mutual Funds Using VIKOR}

Decision making based on more than one attribute is a serious problem. There are many methods named MADM methods that consider and solve this type of problems. One of these methods is VIKOR method.

\subsection{The VIKOR Method}

The VIKOR method is a famous and efficient method that Opricovic (1998) and Opricovic and Tzeng (2002) proposed it for the first time. The VIKOR term has a Serbian etymon and is the abbreviation of this phrase: VlseKriterijumska Optimizacija I Kompromisno Resenje. It means multi criteria optimization and compromise solution (sanayei et al, 2010). The VIKOR method is an extension of $\mathrm{L}_{p}$ - metric method. The $\mathrm{L}_{\mathrm{p}}-$ metric method tries to minimize the distinction between the ideal solutions and objective functions. This method minimizes the function that is shown in Eq. (1).

$$
L_{p, j}=\left\{\sum_{i=1}^{n}\left[\frac{w_{i}\left(f_{i}^{*}-f_{i j}\right)}{f_{i}^{*}-f_{i}^{-}}\right]^{p}\right\}^{1 / p}, j=1,2, \ldots, J, \quad 1 \leq P \leq \infty
$$

Where $\mathrm{J}$ is the number of alternatives, $\mathrm{n}$ is the number of criterions, $f_{i j}$ is the value of ith criterion function for jth alternative, $w_{i}$ is the weight of ith criteria, $f_{i}^{*}$ is the best $f_{i j}$ and $f_{i}^{-}$is the worst $f_{i j}$ (Opricovic and Tzeng, 2004).

The VIKOR method considers $L_{1, j}$ and $L_{\infty, j}$ functions and follows these steps:

Step 1: determine $f_{i}^{*}$ and $f_{i}^{-}$as Eqs. (2), (3).

$$
\begin{aligned}
& f_{i}^{*}=\left\{\begin{array}{c}
\max _{j} f_{i j}, \text { for benefit criteria } \\
\min _{j} f_{i j}, \text { for cost criteria }
\end{array}\right\} j=1,2, \ldots, J \\
& f_{i}^{-}=\left\{\begin{array}{c}
\max _{j} f_{i j}, \text { for cost criteria } \\
\min _{j} f_{i j}, \text { for benefit criteria }
\end{array}\right\} j=1,2, \ldots, J
\end{aligned}
$$

Step 2: compute values $S_{j}$ and $R_{j}$ for $\mathrm{j}=1,2, \ldots$, J by Eqs. (4), (5). ( $\mathrm{S}_{\mathrm{j}}$ is defined based on $\mathrm{L}_{1, \mathrm{j}}$ function and $\mathrm{R}_{\mathrm{j}}$ 
is defined based on $\mathrm{L}_{\infty, \mathrm{j}}$ function).

$$
\begin{array}{r}
S_{j}=\sum_{i=1}^{n} \frac{w_{i}\left(f_{i}^{*}-f_{i j}\right)}{f_{i}^{*}-f_{i}^{-}} \\
R_{j}=\max _{i}\left[\frac{w_{i}\left(f_{i}^{*}-f_{i j}\right)}{f_{i}^{*}-f_{i}^{-}}\right]
\end{array}
$$

$\mathrm{S}^{-}, \mathrm{S}^{*}, \mathrm{R}^{-}$and $R^{*}$ values can be computed by Eqs. (6), (7).

Step 3: compute the values $Q_{\mathrm{j}}$ for $\mathrm{j}=1,2, \ldots, \mathrm{J}$ by Eq. (8).

$$
\begin{aligned}
S^{*}=\min _{j} S_{j}, & S^{-}=\max _{j} S_{j} \\
R^{*}=\min _{i} R_{j}, & R^{-}=\max _{i} R_{j}
\end{aligned}
$$

$$
Q_{j}=\frac{v\left(S_{j}-S^{*}\right)}{S^{-}-S^{*}}+\frac{(1-v)\left(R_{j}-R^{*}\right)}{R^{-}-R^{*}}
$$

Where $\mathrm{v}$ is defined as the maximum group utility and is set to 0.5 in many researches.

Step 4: rank the alternatives using $S_{j}, R_{j}$ and $Q_{j}$ values in decreasing order.

Step 5: If the alternative $\mathrm{a}^{\prime}$ has two following conditions propose it as a compromise solution:

Acceptable advantage: $Q\left(a^{\prime \prime}\right)-Q\left(a^{\prime}\right) \geq \frac{1}{J-1}$

Acceptable stability in decision-making: The alternative $\mathrm{a}^{\prime}$ is ranked the best by $\mathrm{S}$ or/and $\mathrm{R}$.

Where alternative $a^{\prime}$ has the minimum value of $Q\left(Q\left(a^{\prime}\right)=\min _{j} Q_{j}\right)$ and $a^{\prime \prime}$ is ranked the second alternative by $\mathrm{Q}$.

If one of the conditions is not satisfied then a set of compromise solutions is proposed that consist of:

Alternatives $\mathrm{a}^{\prime}$ and $\mathrm{a}^{\prime \prime}$ are compromise solutions if only the condition (b) is not satisfied. Alternatives $\mathrm{a}^{\prime}$, $\mathrm{a}^{\prime \prime}, \ldots, \mathrm{a}^{\mathrm{M}}$ are proposed as compromise solutions if the condition (a) is not satisfied. $\mathrm{a}^{\mathrm{M}}$ is ranked the Mth by $\mathrm{Q}$ and is determined by Eq. (9) for maximum M.

$$
Q\left(a^{M}\right)-Q\left(a^{\prime}\right)<\frac{1}{J-1}
$$

However, VIKOR is used in many researches as an efficient MADM method. For instance Sanayei et al. (2010) used this method for supplier selection problem. San Cristobal (2011) used VIKOR in the selection of a renewable energy project. Peng et al. (2011) proposed VIKOR for evaluating classification algorithms of financial risk prediction. In current study mutual funds are evaluated using VIKOR and with 5 attributes.

\subsection{Attributes}

\subsubsection{Rate of Return}

The net asset value (NAV) is defined as the current value of fund's assets minus its liabilities divided by available number of current shares (Mobius, 2007). Rate of return based on net asset value defined as:

$$
R_{i, t}=\frac{N A V_{i, t}-N A V_{i, t-1}}{N A V_{i, t-1}} * 100 \%
$$

In Eq. (10) $i$ is the number of mutual funds, $R_{i, t}$ is the rate of return of ith fund at time $t$ and $N_{A} V_{i, t}$ is the net asset value of ith fund at time $t$.

\subsubsection{Variance}

$$
\sigma_{i}^{2}=\frac{\sum_{i=1}^{T}\left(R_{i, t}-\bar{R}_{i}\right)}{T}
$$

Where $\bar{R}_{i}$ is the average return rate of T months.

2.2.3 Semivariance 


$$
S V_{i}=\sum_{t=1 ; R_{i, t}<\bar{R}_{i}}^{T}\left(R_{i, t}-\bar{R}_{i}\right) / T
$$

\subsubsection{Treynor Index}

For performance evaluation of portfolios, Treynor (1965) proposed an index like Eq. (13).

$$
T R_{i}=\frac{\bar{R}_{i}-R_{f}}{\beta_{i}}
$$

Where $T_{i}$ is the Treynor index, $\bar{R}_{i}$ is the average rate of return, $R_{f}$ is the return of risk-free asset and $\beta_{i}$ is the measurement of systematic risk and calculated as Eq. (14):

$$
\beta_{i}=\frac{\operatorname{cov}\left(R_{i}, R_{m}\right)}{\sigma_{m}^{2}}
$$

Where $R_{m}$ is the return of market index, $\operatorname{Cov}\left(R_{i}, R_{m}\right)$ is the covariance between the return of mutual fund $i$ and the return of the market index and $\sigma_{\mathrm{m}}^{2}$ is the variance of $\mathrm{R}_{\mathrm{m}}$.

\subsubsection{Sharpe Index}

Sharpe (1966) proposed a ratio for performance evaluation of mutual funds.

$$
S R_{i}=\frac{\bar{R}_{i}-R_{f}}{\sigma_{i}}
$$

In Eq. (15) $\mathrm{SR}_{\mathrm{i}}$ is the Sharpe index and $\sigma_{\mathrm{i}}$ is the standard deviation and called total risk.

\section{Second Stage: Portfolio Optimization}

Portfolio optimization is an old problem that decides to allocate investors' wealth among several assets. This problem has been proposed as a mathematical model since the first study of Markowitz in 1952. The model presented in the researches of Markowitz $(1952,1959)$ is known as basic model.

\subsection{Basic Model}

In financial markets each investor likes to obtain more return and less risk. So that in basic portfolio optimization model there are two objective functions and one constraint. One of the objective functions maximizes the return and the other minimizes the risk. This model is shown in Eq. (16).

$$
\begin{array}{r}
\text { Maximize } R_{p}=\sum_{i=1}^{N} R_{i} \cdot x_{i} \\
\text { Minimize } \sigma_{p}^{2}=\sum_{i=1}^{N} \sum_{j=1}^{N} x_{i} \cdot x_{j} \cdot \sigma_{i j} \\
\text { Subject to } \quad \sum_{i=1}^{N} x_{i}=1 \\
x_{i} \geq 0 \quad i=1,2, \ldots, N
\end{array}
$$

Where $\mathrm{N}$ is the number of assets, $\mathrm{x}_{i}$ is the proportion invested in asset $\mathrm{i}, \mathrm{R}_{\mathrm{i}}$ is the rate of return of ith asset, $\mathrm{R}_{\mathrm{p}}$ is the rate of return of portfolio, $\sigma_{\mathrm{p}}^{2}$ is the variance of portfolio and $\sigma_{\mathrm{ij}}$ is the covariance between the return rates of asset $i$ and asset $j$.

The basic model considers normal distribution for rate of return so that variance is an appropriate risk measure. To solve basic model we can divide it into two models and solve one of them. One model maximizes the return and considers the risk as a constraint and the other minimizes the risk and considers the return as a constraint. Assuming different values for return or risk constraint results efficient frontier. 


\subsection{Mean-Semivariance Model}

The assumption of normal distribution is not always accurate in practice. So that downside risk measures are defined to accurate portfolio optimization problems. Calculation of risk in downside risk measures is based on this theory that when the expected return is higher than mean we have a non-risk situation and when is lower we have risk. There are several studies that consider downside risk measures such as: Vercher et al. (2007), Estrada (2007), Benati \& Rizzi (2007), Gupta et al. (2008), Chang et al. (2009) and Yang et al. (2011). In this study we consider semivariance as a risk measure and rewrite the basic portfolio optimization model using this measure.

$$
\begin{array}{r}
\text { Maximize } R_{p}=\sum_{i=1}^{N} R_{i} \cdot x_{i} \\
\text { Minimize } S V_{p}=\sum_{i=1}^{N} \sum_{j=1}^{N} x_{i} \cdot x_{j} \cdot S V_{i j} \\
\text { Subject to } \quad \sum_{i=1}^{N} x_{i}=1 \\
x_{i} \geq 0 \quad i=1,2, \ldots, N
\end{array}
$$

In Eq. (17) $\mathrm{SV}_{\mathrm{p}}$ is defined as semivariance of portfolio and $\mathrm{SV}_{\mathrm{ij}}$ is cosemivariance (semicovariance) between the return rates of asset $i$ and asset j. cosemivariance can be defined as Eq. (18) (Estrada, 2007). In Eq. 17 the second objective function is non-linear but it is convex and we have a convex optimization model.

\subsection{Cardinality Constraint}

$$
S V_{i j}=E\left\{\min \left[\left(R_{i}-\bar{R}_{i}\right), 0\right] \cdot \min \left[\left(R_{j}-\bar{R}_{j}\right), 0\right]\right\}
$$

Researchers have changed the basic portfolio optimization model by adding objective functions or constraints to make it more accurate. Added objective functions are usually entropy function or liquidity. A common constraint that is used in models is cardinality constraint as in Chang et al. (2000), Gupta et al. (2008), Branke et al. (2009), Chang et al. (2009), Yang et al. (2011) and Golmakani \& Fazel (2011) studies. Cardinality constraint fixes the number of assets in optimized portfolio. In large-scale problems portfolio management is difficult and investors like to have finite assets in their portfolio. For defining cardinality in portfolio optimization models a constraint like Eq. (19) adds to model.

$$
\sum_{i=1}^{N} z_{i}=K
$$

Where $\mathrm{K}$ is cardinality level and $z_{i}$ is a zero-one variable. $z_{i}=1$ if ith asset is held and $z_{i}=0$ otherwise. This constraint makes the model an integer programming problem. The problem has at least two objective functions (return and risk) and because of risk function is non-linear. So we can call this model a multi-objective non-linear integer programming. In large-scale problems solving this model is very hard and forces us to use metaheuristics. On the other hand, in cardinality constrained problems the efficient frontier is discontinuous because of integer variables (Change et al, 2000). In this study, according to cardinality level, best mutual funds are chosen. For example when $\mathrm{K}=6$, we choose six funds that ranked the best based on VIKOR ranking. Then these funds are optimized for determining the proportions of capital that should be invested on.

\subsection{Fuzzy Programming Technique}

Fuzzy programming is an efficient technique for solving multi-objective non-linear problems that is proposed by Zimmermann (1978). Jana et al. (2009) showed that this technique can be applied in portfolio optimization problem. Fuzzy programming technique follows these steps for solving the problem that is shown in Eq. (17):

Step 1: consider the problem as two single objective problems and minimize and maximize the problems with constraint. These solutions are named ideal solutions. $R_{\mathrm{P}}^{*}$ is defined as maximum value of return objective function and $\mathrm{R}_{\mathrm{p}}^{-}, \mathrm{SV}_{\mathrm{p}}^{*}$ and $\mathrm{SV}_{\mathrm{p}}^{-}$are defined likewise.

Step 2: compute the intervals of objective functions. $\Delta \mathrm{R}_{\mathrm{P}}$ is defined as interval of return objective function and 
$\Delta \mathrm{SV}_{\mathrm{p}}$ is defined as interval of risk objective function. These definitions are shown in Eqs. (20), (21).

$$
\begin{gathered}
\Delta R_{p}=R_{p}^{*}-R_{p}^{-} \\
\Delta S V_{p}=S V_{p}^{*}-S V_{p}^{-}
\end{gathered}
$$

Step 3: define membership functions of objectives as Eqs. (22), (23).

$$
\begin{array}{r}
\mu\left(R_{p}\right)=\left\{\begin{array}{lr}
0 & R_{p} \leq R_{p}^{-} \\
\frac{R_{p}-R_{p}^{-}}{\Delta R_{p}} & R_{p}^{-}<R_{p}<R_{p}^{*} \\
1 & R_{p} \geq R_{p}^{*}
\end{array}\right. \\
\mu\left(S V_{p}\right)=\left\{\begin{array}{lc}
0 & S V_{p} \leq S V_{p}^{-} \\
\frac{S V_{p}^{*}-S V_{p}}{\Delta S V_{p}} & S V_{p}^{-}<S V_{p}<S V_{p}^{*} \\
1 & S V_{p} \geq S V_{p}^{*}
\end{array}\right.
\end{array}
$$

Step 4: define $\alpha_{R}$ as the percentage that return objective function is neared to its optimized solution or minimum value of its membership function and define $\alpha_{S V}$ likewise. Now we can write Eqs. (24), (25).

$$
\begin{gathered}
\alpha_{R} \leq \mu\left(R_{p}\right) \rightarrow \alpha_{R} \leq \frac{R_{p}-R_{p}^{-}}{\Delta R_{p}} \rightarrow R_{p} \geq R_{p}^{-}+\alpha_{R} \cdot \Delta R_{p} \\
\alpha_{S V} \leq \mu\left(S V_{p}\right) \rightarrow \alpha_{S V} \leq \frac{S V_{p}^{*}-S V_{p}}{\Delta S V_{p}} \rightarrow S V_{p} \leq S V_{p}^{*}-\alpha_{S V} \cdot \Delta S V_{p}
\end{gathered}
$$

Now we can rewrite the model that is proposed in Eq. (17) as a single objective model that operation research softwares can solve it easily.

$$
\begin{array}{r}
\text { Maximize } \quad L=w_{R} \cdot \alpha_{R}+w_{S V} \cdot \alpha_{S V} \\
\text { Subject to: } R_{p} \geq R_{p}^{-}+\alpha_{R} \cdot \Delta R_{p} \\
S V_{p} \leq S V_{p}^{*}-\alpha_{S V} \cdot \Delta S V_{p} \\
\quad \sum_{i=1}^{N} x_{i}=1 \\
x_{i} \geq 0, \quad i=1,2, \ldots, N
\end{array}
$$

Where $\mathrm{L}$ is the percent that objective functions near to their optimized solution additionally, $\mathrm{w}_{\mathrm{R}}$ is the weight of return objective function and $\mathrm{w}_{\mathrm{SV}}$ is the weight of risk objective function.

\section{Numerical Example}

In this section we show our proposed methodology in a computational example. There are 92 mutual funds in our sample from NASDAQ. In first stage, these funds are studied between years 2007-2009 and in monthly data. Rate of return, variance, semivariance, Treynor index and Sharpe index are extracted from 36 data. We have a MADM problem with 92 alternatives and 5 attributes. The VIKOR method is used for ranking of funds. We consider equal weights $(1 / 3)$ for return, risk and portfolio indices. Because we have two measures for risk and two for portfolio indices the weight of variance, semivariance, Treynor and Sharpe index is assumed 1/6. Ranking of best funds and their attributes is shown in table 1 for top ten funds.

Table 1. Ranking of funds and their attributes

\begin{tabular}{rrrrrr}
\hline $\begin{array}{r}\text { Fund } \\
\text { number }\end{array}$ & $\begin{array}{r}\text { Return } \\
\text { rate }\end{array}$ & Variance & $\begin{array}{r}\text { Semi } \\
\text { variance }\end{array}$ & $\begin{array}{r}\text { Treynor } \\
\text { index }\end{array}$ & $\begin{array}{r}\text { Sharpe } \\
\text { index }\end{array}$ \\
\hline 41 & 0.93 & 220.77 & 99.24 & 14.55 & 0.66 \\
2 & 0.27 & 55.01 & 21.04 & 0.64 & 0.13 \\
75 & 0.57 & 201.46 & 117.57 & 8.97 & 0.43 \\
5 & 0.8 & 331.68 & 163.85 & 6.8 & 0.38
\end{tabular}




$\begin{array}{rrrrrr}92 & 0.83 & 486.41 & 212.65 & 6.74 & 0.4 \\ 12 & 0.64 & 314.49 & 154.11 & 6.04 & 0.32 \\ 19 & 0.13 & 46.68 & 22.01 & -6.18 & -0.08 \\ 34 & 0.42 & 163.61 & 86.69 & 3.92 & 0.2 \\ 66 & 0.78 & 1120.03 & 685.35 & 7.25 & 0.45 \\ 91 & 0.66 & 448.48 & 195.56 & 5.18 & 0.34\end{array}$

All of the funds are ranked and compromise solutions are obtained. Then, 4 levels considered for cardinality: $\mathrm{K}=2,4,6,8$. when $\mathrm{K}=2$, funds number 41 and 2 are chosen for portfolio optimization and when $\mathrm{K}=4$ funds number 41, 2, 75 and 5 etc. From attributes return rate and semivariance are remained for next stage. In second stage a mean-semivariance portfolio optimization model is written for chosen funds according to cardinality level. For example for $\mathrm{K}=4$ we have a model like the model is shown in Eq. (27). For making this model a cosemivariance matrix is computed.

$$
\begin{gathered}
\text { Maximize } L=w_{R} \cdot \alpha_{R}+w_{S V} \cdot \alpha_{S V} \\
\text { Subject to: } 0.93 x_{1}+0.27 x_{2}+0.57 x_{3}+0.8 x_{4} \geq 0.27+0.66 \alpha_{R} \\
99.24 x_{1}^{2}+21.04 x_{2}^{2}+10.49 x_{1} x_{2}+117.57 x_{3}^{2}+163.85 x_{4}^{2}+87.41 x_{1} x_{3}+45.67 x_{1} x_{4} \\
+7.74 x_{2} x_{3}+48.14 x_{2} x_{4}+225.72 x_{3} x_{4} \leq 163.85-145.9 \alpha_{S V} \\
\sum_{i=1}^{4} x_{i}=1 \\
x_{i} \geq 0, \quad i=1,2,3,4
\end{gathered}
$$

Lingo 11 software can solve this problem. In all problems $w_{R}+w_{S V}$ is assumed equal one. $w_{R}$ is started from zero to one with steps equal 0.1 . The results of solving this problem is shown in table 2 .

Table 2. Computed values for return and risk of portfolio and investment proportions

\begin{tabular}{llllllll}
\hline & & $R_{p}$ & $S V_{p}$ & $x_{1}$ & $x_{2}$ & $x_{3}$ & $x_{4}$ \\
\hline$w_{R}=0$ & $w_{S V}=1$ & 0.364 & 17.667 & 0.099 & 0.812 & 0.089 & 0 \\
$w_{R}=0.1$ & $w_{S V}=0.9$ & 0.413 & 18.31 & 0.175 & 0.74 & 0.085 & 0 \\
$w_{R}=0.2$ & $w_{S V}=0.8$ & 0.473 & 20.769 & 0.269 & 0.651 & 0.08 & 0 \\
$w_{R}=0.3$ & $w_{S V}=0.7$ & 0.606 & 29.426 & 0.413 & 0.469 & 0 & 0.118 \\
$w_{R}=0.4$ & $w_{S V}=0.6$ & 0.747 & 46.875 & 0.56 & 0.236 & 0 & 0.204 \\
$w_{R}=0.5$ & $w_{S V}=0.5$ & 0.892 & 73.349 & 0.715 & 0 & 0 & 0.285 \\
$w_{R}=0.6$ & $w_{S V}=0.4$ & 0.896 & 74.538 & 0.748 & 0 & 0 & 0.252 \\
$w_{R}=0.7$ & $w_{S V}=0.3$ & 0.903 & 77.57 & 0.803 & 0 & 0 & 0.197 \\
$w_{R}=0.8$ & $w_{S V}=0.2$ & 0.918 & 87.59 & 0.913 & 0 & 0 & 0.087 \\
$w_{R}=0.9$ & $w_{S V}=0.1$ & 0.93 & 99.238 & 1 & 0 & 0 & 0 \\
$w_{R}=1$ & $w_{S V}=0$ & 0.93 & 99.238 & 1 & 0 & 0 & 0 \\
\hline
\end{tabular}

Considering 11 levels for $w_{R}$ and $w_{S v}$ results an efficient frontier. Efficient frontiers for $K=4$ and other cardinality levels are shown in Figs. 1-4. Each efficient frontier is compared with unconstrained efficient frontier and all of the efficient frontiers are compared in Fig. 5. 


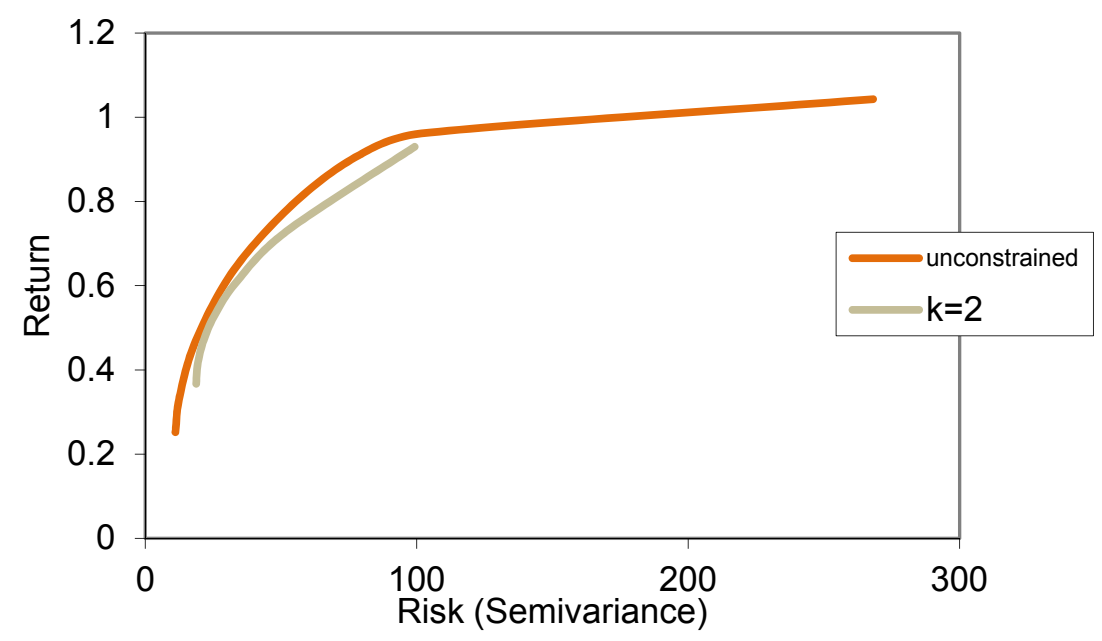

Figure 1. Efficient frontier considering cardinality level=2

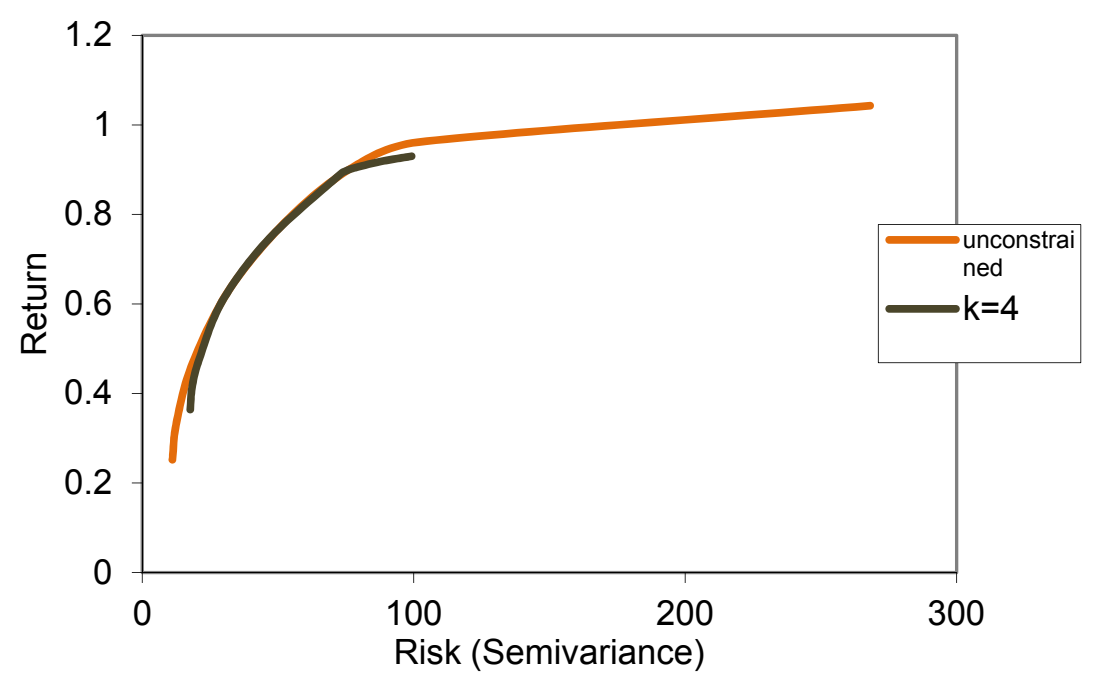

Figure 2. Efficient frontier considering cardinality level=4

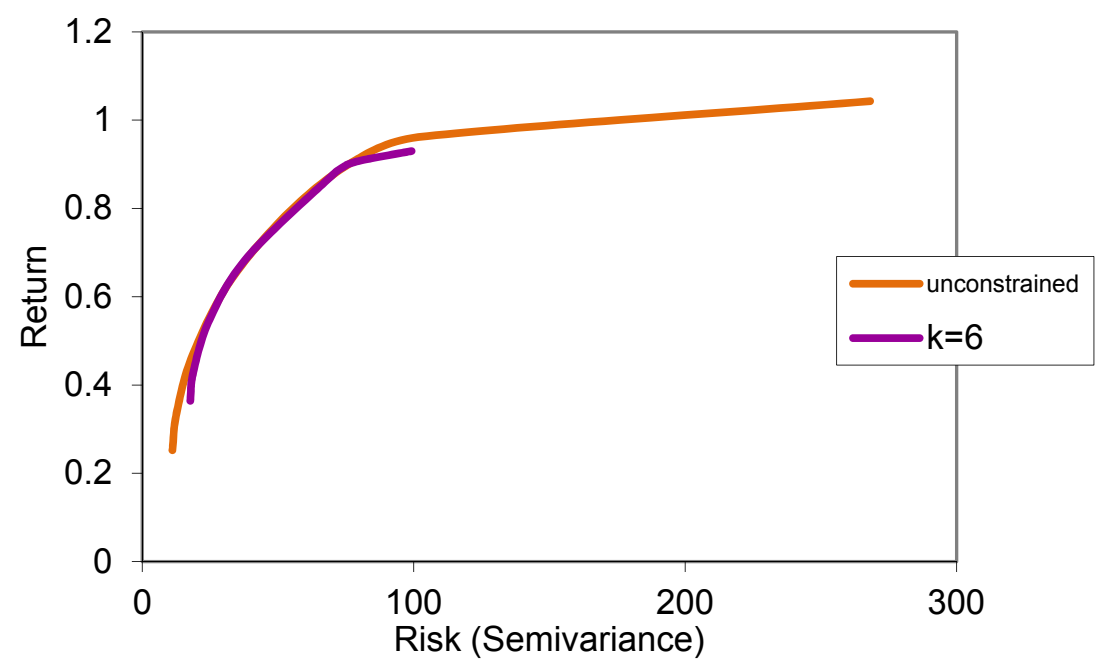

Figure 3. Efficient frontier considering cardinality level=6 


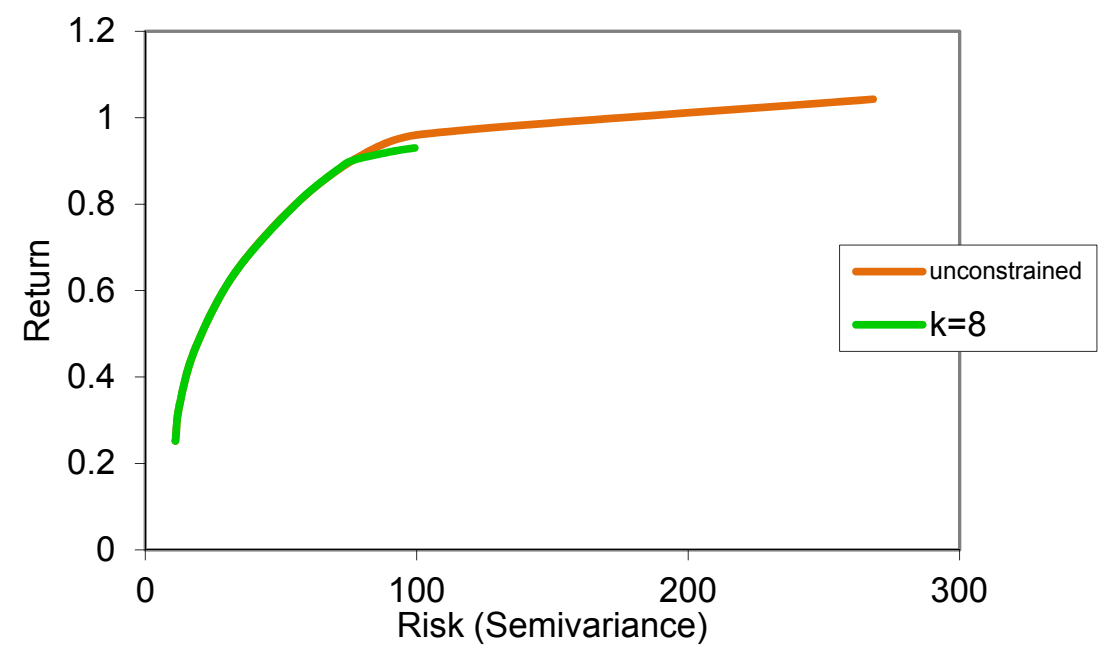

Figure 4. Efficient frontier considering cardinality level=8

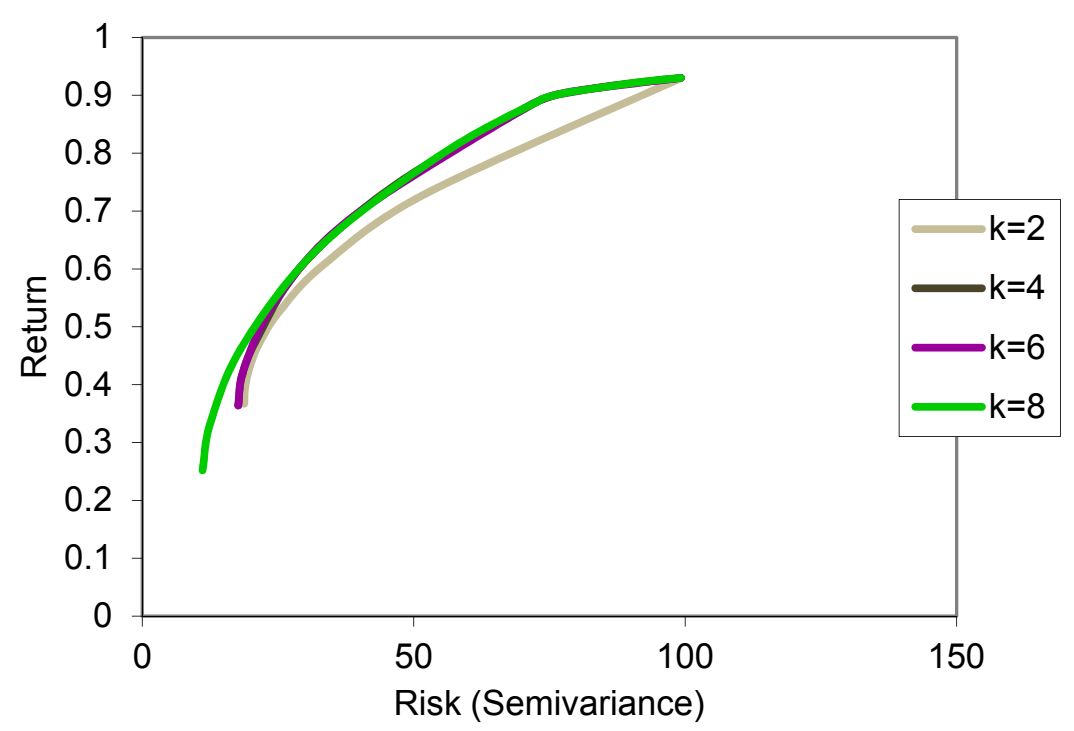

Figure 5. Efficient frontiers considering different cardinality levels

As shown in Figures 1-4 increasing cardinality level leads to near constrained and unconstrained solutions. When $\mathrm{k}=2$ the difference between constrained efficient frontier and unconstrained is considerable but when we increase cardinality level this difference is decreased. As shown in Fig. 4 when $\mathrm{k}=8$ both of efficient frontiers are matched in almost every risk level but unconstrained efficient frontier dominated constrained efficient frontier and it is not surprising because in unconstrained solution there are 92 funds and in constrained solution there are only 8 funds. It is important that using proposed methodology leads to similar results between unconstrained solutions and cardinality constrained solutions. In other words, we approximately obtain the unconstrained solutions with 8 funds and this is the contribution of this study. The small difference between constrained and unconstrained efficient frontier in Fig. 4 is because of one fund that was not in our portfolio in $k=8$. This fund has appropriate return rate but other characteristics such as its Treynor index and Sharpe index is not appropriate enough to place in best mutual funds portfolio. In table 3 the characteristics of this fund (number 40) and the fund that ranked the best in VIKOR ranking (number 41) are compared. On the other words this difference is because of effectiveness of Treynor index and Sharpe index in our methodology. Fig. 5 shows the comparison of different cardinality levels. As shown in this figure $\mathrm{k}=8$ efficient frontier dominates other efficient frontiers and $\mathrm{k}=4$ and $\mathrm{k}=6$ efficient frontiers are matched approximately. 
Table 3. A comparison between two funds

\begin{tabular}{llllll}
\hline Fund number & Return rate & variance & semivariance & Treynor index & Sharpe index \\
\hline 41 & 0.93 & 220.77 & 99.24 & 14.55 & 0.66 \\
40 & 1.04 & 442.33 & 210.05 & -3.04 & -0.05 \\
\hline
\end{tabular}

\section{Conclusion}

Mutual funds decide to play the role of diversification as an institute in financial markets. In current study a new two-stage methodology for performance evaluation of mutual funds is proposed. In first stage 5 characteristics are measured for all of mutual funds. The characteristics are return rate, variance, semivariance, Treynor index and Sharpe index. The VIKOR method is used as a MADM method for ranking these funds. The funds are ranked based on 5 characteristics and considering equal weights for return, risk and portfolio indices. In second stage the best funds are chosen considering cardinality level. When cardinality level is equal 2 the first and second funds according to VIKOR ranking are used. 4 levels are assumed as cardinality levels. Then a multi-objective portfolio optimization model is written. In this model semivariance is used as a downside risk measure. This model is solved using fuzzy technique programming and efficient frontiers are obtained.

Results show that when cardinality level increases we can have appropriate solutions. In this study these solutions are observed in cardinality level equal 8 . In this cardinality level the cardinality constrained efficient frontier and unconstrained efficient frontier are matched approximately. Because in models that consider cardinality constraint, the efficient frontier is discontinuous, obtaining continuous efficient frontier was our success.

In this study we have considered cardinality constraint without using integer programming or metaheuristics. Future works can focus on other constraints in portfolio optimization model and facilitate its solving. As another work and based on this methodology other MADM methods and portfolio optimization models can be used.

\section{References}

Anagnostopoulos, K. P., \& Mamanis, G. (2010). A portfolio optimization model with three objectives and discrete variables. Expert Systems With Applications, 38, 14208-14217. http://dx.doi.org/10.1016/j.cor.2009.09.009

Anagnostopoulos, K. P., \& Mamanis, G. (2011). The mean-variance cardinality constrained portfolio optimization problem: An experimental evaluation of five multi objective evolutionary algorithms. Computers \& Operations Research, 37, 1285-1297. http://dx.doi.org/ 10.1016/j.eswa.2011.04.233

Basso, A., \& Funari, S. (2001). A data envelopment analysis approach to measure the mutual fund performance. European Journal of Operational Research, 135, 477-492. http://dx.doi.org/10.1016/S0377-2217(00)0031-8

Benati, S., \& Rizzi, R. (2007). A mixed integer linear programming formulation of optimal mean/Value-at-Risk portfolio problem. European Journal of Operational Research, 176, 423-434. http://dx.doi.org/10.1016/j.ejor.2005.07.020

Branke, J., Scheckenbach, B., Stein, M., Deb, K., \& Schmeck, H. (2009). Portfolio optimization with an envelope-based multi-objective evolutionary algorithm. European Journal of Operational Research, 199, 684-693. http://dx.doi.org/10.1016/j.ejor.2008.01.054

Chang, C. H., Lin, J. J., Lin, J. H., \& Chiang, M. C. (2010). Domestic open-end equity mutual fund performance evaluation using extended TOPSIS method with different distance approaches. Expert Systems with Applications, 37, 4642-4649. http://dx.doi.org/10.1016/j.eswa.2009.12.044

Chang, T. J., Meade, N., Beasley, J. E., \& Sharaiha, Y. M. (2000). Heuristics for cardinality constrained portfolio

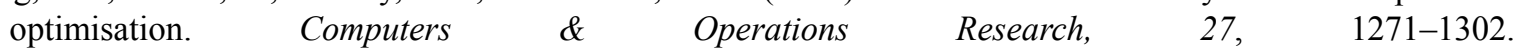
http://dx.doi.org/10.1016/S0305-0548(99)00074-X

Chang, T. J., Yang, S. C., \& Chang, K. J. (2009). Portfolio optimization problem in different risk measures using genetic algorithm. Expert Systems With Applications, 36, 10529-10537. http://dx.doi.org/10.1016/j.eswa.2009.02.062

Chen, L. H., \& Huang, L. (2009). Portfolio optimization of equity mutual funds with fuzzy return rates and risks. Expert Systems with Application, 36, 3720-3727. http://dx.doi.org/10.1016/j.eswa.2008.02.027

Estrada, J. (2007). Mean-semivariance behavior: downside risk and capital asset pricing. International Review of Economics and Finance, 16, 169-185. http://dx.doi.org/ 10.1016/j.iref.2005.03.003

Golmakani, H. R., \& Fazel, M. (2011). Constrained portfolio selection using Particle Swarm Optimization. Expert 
Systems With Applications, 38, 8327-8335. http://dx.doi.org/10.1016/j.eswa.2011.01.020

Gupta, P., Mehlawat, M. K., \& Saxena, A. (2008). Asset portfolio optimization using fuzzy mathematical programming. Information Sciences, 178, 1734-1755. http://dx.doi.org/10.1016/j.ins.2007.10.025

Jana, P., Roy, T. K., \& Mazumder, S. K. (2009). Multi-objective possibilistic model for portfolio selection with transaction cost. Journal of Computational and Applied Mathematics, 228, 188-196. http://dx.doi.org/10.1016/j.cam.2008.09.008

Lin, C. C., \& Liu, Y. T. (2008). Genetic algorithms for portfolio selection problems with minimum transaction lots. European Journal of Operational Research, 185, 393-404. http://dx.doi.org/10.1016/j.ejor.2006.12.024

Markowitz, H. M. (1952). Portfolio selection. The Journal of Finance, 7, 77-91.

Markowitz, H. M. (1959). Portfolio selection: efficient diversification of investments. New York: Wiley.

Mobius, M. (2007). Mutual funds: an introduction to the core concepts. Singapore: John Wiley \& Sons (Asia) Pte Ltd.

Murthi, B. P. S., Choi, Y. K., \& Desai, P. (1997). Efficiency of mutual funds and portfolio performance measurement: A non-parametric approach. European Journal of Operational Research, 98, 408-418. http://dx.doi.org/10.1016/S0377-2217(96)00356-6

Opricovic, S. (1998). Multi-criteria optimization of civil engineering systems. Belgrade: Faculty of Civil Engineering.

Opricovic, S., \& Tzeng, G. H. (2002). Multicriteria planning of post-earthquake sustainable reconstruction. Computer-Aided Civil and Infrastructure Engineering, 17(3), 211-220.

Opricovic, S., \& Tzeng, G. H. (2004). Compromise solution by MCDM methods: A comparative analysis of VIKOR and TOPSIS. European Journal of Operational Research, 156(2), 445-455. http://dx.doi.org/10.1016/S0377-2217(03)00020-1

Peng, Y., Wang, G., Kou, G., \& Shi, Y. (2011). An empirical study of classification algorithm evaluation for financial risk prediction. Applied Soft Computing, 11, 2906-2915. http://dx.doi.org/10.1016/j.asoc.2010.11.028

San Cristobal, J. R. (2011). Multi-criteria decision-making in the selection of a renewable energy project in spain: the VIKOR method. Renewable Energy, 36, 498-502. http://dx.doi.org/10.1016/j.renene.2010.07.031

Sanayei, A., Farid-Mousavi, S., \& Yazdankhah, A. (2010). Group decision making process for supplier selection with VIKOR under fuzzy environment. Expert Systems With Applications 37, 24-30. http://dx.doi.org/10.1016/j.eswa.2009.04.063

Sharpe, W. F. (1966). Mutual fund performance. Journal of Business, 39, 119-138.

Treynor, J. (1965). How to rate management of investment funds. Harvard Business Review, 43, 63-75.

Woodside-Oriakhi, M., Lucas, C., \& Beasley, J. E., (2011). Heuristic algorithms for the cardinality constrained efficient frontier. European Journal of Operational Research, 213, 538-550. http://dx.doi.org/10.1016/j.ejor.2011.03.030

Xia, Y., Wang, S., \& Deng, X., (2001). A compromise solution to mutual funds portfolio selection with transaction costs. European Journal of Operational Research, 134, 564-581. http://dx.doi.org/10.1016/S0377-2217(00)00278-2

Yang, S. C., Lin, T. L., Chang, T. J., \& Chang, K. J. (2011). A semi-variance portfolio selection model for military investment assets. Expert Systems With Applications, 38, 2292-2301. http://dx.doi.org/10.1016/j.eswa.2010.08.017

\section{Copyrights}

Copyright for this article is retained by the author(s), with first publication rights granted to the journal.

This is an open-access article distributed under the terms and conditions of the Creative Commons Attribution license (http://creativecommons.org/licenses/by/3.0/). 